\title{
A cross-sectional examination of socio-demographic and school-level correlates of children's school travel mode in Ottawa, Canada
}

\author{
Richard Larouche ${ }^{1 *}$, Jean-Philippe Chaput ${ }^{1,2}$, Geneviève Leduc ${ }^{1}$, Charles Boyer ${ }^{1}$, Priscilla Bélanger ${ }^{1}$, \\ Allana G LeBlanc ${ }^{1}$, Michael M Borghese ${ }^{1}$ and Mark S Tremblay ${ }^{1,2}$
}

\begin{abstract}
Background: Active school transport (AST) is an important source of children's daily physical activity (PA). However, decreasing rates of AST have been reported in multiple countries during the last decades. The purpose of the present study was to examine the socio-demographic and school-level correlates of AST.

Methods: A stratified sample of children ( $N=567$, mean age $=10.0$ years; $57.8 \%$ female) was recruited in the Ottawa area. Four sources of data were used for analyses: 1 ) child questionnaire including questions on school travel mode and time; 2) parent questionnaire providing information on household socio-demographic characteristics; 3) school administrator survey assessing school policies and practices pertaining to PA; and 4) school site audit performed by the study team. Generalized linear mixed models were used to identify socio-demographic and school-level correlates of AST while controlling for school clustering.
\end{abstract}

Results: Individual factors associated with higher odds of AST were male gender ( $\mathrm{OR}=1.99 ; 95 \% \mathrm{Cl}=1.30-3.03)$, journey time $<5$ minutes vs. $>15$ minutes $(\mathrm{OR}=2.26 ; 95 \% \mathrm{Cl}=1.17-4.37)$, and $5-15$ minutes vs. $>15$ minutes $(\mathrm{OR}=2.27 ; 95 \% \mathrm{Cl}=1.27-4.03)$. Children were more likely to engage in AST if school administrators reported that crossing guards were employed $(\mathrm{OR}=2.29 ; 95 \% \mathrm{Cl}=1.22-4.30)$, or if they expressed major or moderate concerns about crime in the school neighbourhood $(\mathrm{OR}=3.34 ; 95 \% \mathrm{Cl}=1.34-8.32)$. In schools that identified safe routes to school and where traffic calming measures were observed, children were much more likely to engage in AST compared to schools without these features ( $\mathrm{OR}=7.87 ; 95 \% \mathrm{Cl}=2.85-21.76)$. Moreover, if only one of these features was present, this was not associated with an increased likelihood of AST.

Conclusion: These findings suggest that providing crossing guards may facilitate AST. Additionally, there was a synergy between the identification of safe routes to school and the presence of traffic calming measures, suggesting that these strategies should be used in combination.

Keywords: Active travel, Safe routes to school, Social ecological models, School policies, Built environment

\section{Background}

Previous systematic reviews indicate that children and youth using active modes of transportation such as walking or cycling to travel to/from school (e.g., active school transport; AST) accumulate more daily physical activity (PA) than those who are driven by car or bus $[1,2]$. In

\footnotetext{
* Correspondence: rlarouche@cheo.on.ca

'Healthy Active Living and Obesity Research Group, Children's Hospital of Eastern Ontario Research Institute, 401 Smyth Road, Room R242, Ottawa, ON K1H 8 L1, Canada

Full list of author information is available at the end of the article
}

addition, children who cycle to/from school have higher cardiovascular fitness than their peers using motorized travel modes $[1,3,4]$. Other investigators have also reported that AST was associated with greater academic achievement [5] and reduced stress [6].

Together, these findings suggest that AST should be promoted as a strategy to improve children's health and well-being. However, the proportion of children engaging in AST has decreased markedly over the last few decades in many countries including Australia [7], Canada [8], Switzerland [9], and the United States [10]. 
Furthermore, interventions aimed at promoting AST have generally achieved only modest shifts from car travel to AST $[11,12]$.

To inform the development of more effective interventions, a better understanding of the correlates of AST is warranted. Current theoretical models that seek to predict AST are typically based on the social ecological approach $[13,14]$ which posits that behaviour is determined by the interactions between multiple levels of influence. These include characteristics of the individual, the social environment, the built environment, public policies, and the physical environment $[15,16]$. To date, few studies have assessed school-level factors associated with AST while controlling for relevant individual characteristics and clustering within schools [17-19]. Rooted in a social ecological approach, such investigations have the potential to unravel interactions between multiple levels of influence and to identify promising intervention strategies [20].

Therefore, the present study investigated the sociodemographic and school-level correlates of AST among 10-year-old children in Ottawa, Canada. Data were collected from multiple sources (child and parent questionnaire, school administrator survey and school audit) in order to examine multiple levels of influence. The overarching goal was to identify factors accounting for the betweenschool variation in AST to inform the development of future interventions.

\section{Methods}

\section{Participants}

The present study used data from the Canadian site of the International Study of Childhood Obesity, Lifestyle and the Environment (ISCOLE). Based on the socialecological model, this 12-country cross-sectional study aimed to collect data on the correlates of childhood obesity at the individual, family, neighbourhood, and school environment levels. Greater details concerning the study design are available elsewhere [21]. The Canadian site consisted of 567 grade five students (239 boys and 328 girls; 9-11 years of age) recruited between September 2012 and May 2013 in 26 schools within the Ottawa region. The Ottawa-Gatineau region is the fourth largest census metropolitan area in Canada, and the population is predominantly English speaking, albeit with a large French speaking minority [22]. Schools were stratified into four groups: English Public ( $n=393 ; 69.3 \%)$, French Public $(n=60 ; 10.6 \%)$, English Catholic ( $\mathrm{n}=75 ; 13.2 \%)$, and French Catholic $(\mathrm{n}=39,6.8 \%)$. The response rate was $50 \%$. This study was approved by the research ethics boards of the Children's Hospital of Eastern Ontario, and the participating school boards. Written informed parental consent and child assent were obtained for all participants.

\section{Procedures}

First, trained study staff administered a child questionnaire in schools [21]. Travel mode was assessed with one item ("in the last week you were in school, the MAIN part of your journey to school was by"). Response options were: 1) walking; 2) bicycle, rollerblade, skateboard, scooter; 3) bus, train, tram, underground, or boat; 4) car, motorcycle, or moped; 5) other. Children who reported "other" were asked to specify their travel mode. Children were also asked to report their usual school journey time. Categories were: 1) <5 minutes; 2) 5-15 minutes; 3) 16-30 minutes; 4) 31 minutes to 1 hour; 5) $>1$ hour.

Second, socio-demographic variables were obtained through a parent questionnaire [21] (Table 1). Information on annual household income (eight levels), mother's education (six levels), number of functioning motorized vehicles (five levels), and the child's gender and ethnicity were examined in the present analyses. Two school-level socio-demographic variables were considered in analyses: school language (English or French) and school board (Public or Catholic).

Third, the school environment was assessed with a questionnaire completed by a school administrator (e.g., the principal). Questionnaire items were taken from the School Health Environment Survey which is a component of the Canadian School Health Action, Planning and Evaluation System [23]. Satisfactory testretest reliability and convergent validity between school administrators and teachers was noted in a separate purposive sample of Ontario educators, as reported in details elsewhere [24]. Of particular interest, administrators were questioned about the existence of school policies related to PA and healthy eating, on school facilities that may influence children's mobility (i.e., the presence and safety of bike racks) and on school-based promotion of AST (i.e., identification of safe routes to school, organization of events such as walk to school days). They were also asked whether they perceived religious tensions, litter in the streets, drugs/drinking, gangs, heavy traffic, vacant/shabby houses, and crime as a problem in the school neighbourhood on 4point Likert scales ranging from "major problem" to "not a problem", with a "don't know" option for each question. Eighteen variables from the administrator questionnaire were considered for the present analyses (Table 2).

Fourth, a school audit was performed by a single trained examiner at each participating school [21] to examine opportunities for PA in the school environment. A photo dictionary was created to standardize data collection procedures. Most of the included items were taken from the Sport, Physical Activity and Eating Behaviour: Environmental Determinants in Young People (SPEEDY) study audit [25] which has shown acceptable inter-rater reliability and construct validity (as assessed 
Table 1 Socio-demographic correlates of active school transport

\begin{tabular}{|c|c|c|c|c|c|c|}
\hline Variable & Categories & Frequency & Percentage & OR & $95 \% \mathrm{Cl}$ & $p$ \\
\hline \multirow[t]{2}{*}{ Gender } & Boys & 239 & 42.2 & 1.98 & $1.31-2.98$ & .001 \\
\hline & Girls & 328 & 57.8 & & Reference & \\
\hline \multirow[t]{2}{*}{ School travel mode } & Active & 199 & 35.1 & & N/A & \\
\hline & Public transport & 368 & 64.9 & & & \\
\hline \multirow[t]{3}{*}{ School travel time } & $<5$ minutes & 134 & 23.6 & 2.39 & $1.24-4.63$ & .010 \\
\hline & 5-15 minutes & 289 & 51.0 & 2.44 & $1.37-4.34$ & .002 \\
\hline & $>15$ minutes & 144 & 25.4 & & Reference & \\
\hline \multirow[t]{3}{*}{ Household income } & $<\$ 60,000$ & 105 & 19.3 & 0.77 & $0.40-1.49$ & .439 \\
\hline & $\$ 60,000-\$ 139,999$ & 231 & 42.4 & 0.87 & $0.54-1.40$ & .552 \\
\hline & $\geq \$ 140,000$ & 209 & 38.3 & & Reference & \\
\hline \multirow[t]{3}{*}{ Mother's education } & $<$ College & 85 & 15.2 & 1.52 & $0.84-2.76$ & .169 \\
\hline & College & 142 & 25.4 & 0.72 & $0.43-1.21$ & .216 \\
\hline & University & 331 & 59.3 & & Reference & \\
\hline \multirow[t]{2}{*}{ Motorized vehicles } & $\leq 1$ & 236 & 42.1 & 1.25 & $0.81-1.94$ & .321 \\
\hline & $\geq 2$ & 325 & 57.9 & & Reference & \\
\hline \multirow[t]{2}{*}{ School language } & French & 99 & 17.5 & 0.19 & $0.06-0.64$ & .007 \\
\hline & English & 468 & 82.5 & & Reference & \\
\hline \multirow[t]{2}{*}{ School board } & Catholic & 114 & 20.1 & 0.61 & 0.09-1.06 & .061 \\
\hline & Public & 453 & 79.9 & & Reference & \\
\hline
\end{tabular}

Note: Odds ratios for engaging in active transportation were estimated using generalized linear mixed models adjusted only for school clustering.

with accelerometry-measured PA). Fourteen items were retained for the present analyses (Table 3). Twelve items pertained to walking and cycling provisions in the school environment. The auditor was asked to indicate whether these items were visible from any school entrance. A similar item on the visibility of fast food restaurants from any of the school entrances was added by the ISCOLE team [21]. Finally, land use (as perceived by the auditor) was assessed with a single question ("Is the area around the school predominantly?"): 1) "residential"; 2) "open fields/ commons/parks"; 3) "business/retail"; 4) "a mixture of different land uses". Previous research shows that land use mix is an important correlate of adults' active transport, although its influence on children's mobility remains equivocal [26].

\section{Data treatment}

Children's travel mode was dichotomized as active (walk, cycle, etc.) vs. inactive (car, bus, etc.). Participants who reported 'other' modes $(\mathrm{n}=2)$ indicated running or jogging; hence, they were classified as active travelers. Given the large number of categories in the questionnaires, socio-demographic variables were recoded based on the observed distributions (Table 1). School travel time was categorized as 1) $<5$ minutes; 2) 5-15 minutes; 3) $>15$ minutes. Most journeys longer than 15 minutes were done by car or bus, so collapsing the response options did not have a marked influence on the results.
Annual household income was categorized as 1$)<\$ 60,000$; 2) $\$ 60,000-\$ 139,999 ; 3) \geq \$ 140,000$. Mother's education was categorized as 1$)<$ college; 2 ) college; and 3) university. Motorized vehicle ownership was dichotomized as one or none versus two or more. Given that few administrators perceived major safety problems in the school neighbourhood, their responses to these seven items were recoded as 1) major/moderate problem; 2) minor problem; and 3) not a problem/don't know. In addition, if administrators did not know whether their school identified safe routes to school, it was assumed that they did not. This assumption was based on the fact that school travel planning [27] is a whole-of-school intervention that mobilises school administrators, teachers, students, and the broader community; thus, administrators would be expected to know if such a scheme was in place at their school. Finally, land use was recoded as "residential" versus "others".

\section{Statistical analyses}

Generalized linear mixed models (GLMM) with a binomial distribution and logit link were used to examine the socio-demographic and school-level correlates of children's travel mode (e.g., active vs. inactive) following analytical procedures described by Cerin [20]. First, a model was fitted with only school entered as a random effect to determine the within-school intra-class correlation coefficient (ICC). Specifically, the greater 
Table 2 School-level correlates of active school transport, as reported by school administrators

\begin{tabular}{|c|c|c|c|c|c|c|}
\hline Variable & Categories & Frequency & Percentage & OR & $95 \% \mathrm{Cl}$ & $\mathbf{p}$ \\
\hline \multirow[t]{2}{*}{ Physical activity policies* } & Existing policies & 501 & 88.4 & 1.99 & $0.38-10.46$ & .415 \\
\hline & Practices & 66 & 11.6 & & Reference & \\
\hline \multirow[t]{2}{*}{ Healthy eating policies* } & Existing policies & 499 & 88.0 & 0.51 & $0.10-2.58$ & .413 \\
\hline & Practices & 68 & 12.0 & & Reference & \\
\hline \multirow[t]{2}{*}{ Identify safe routes to school } & Yes & 289 & 51.0 & 3.63 & $1.39-9.44$ & .008 \\
\hline & No & 278 & 49.0 & & Reference & \\
\hline \multirow[t]{2}{*}{ Provides crossing guards } & Yes & 284 & 50.1 & 5.75 & $2.52-13.10$ & $<.001$ \\
\hline & No & 283 & 49.9 & & Reference & \\
\hline \multirow[t]{2}{*}{ Designate car free zone } & Yes & 238 & 42.0 & 1.52 & $0.52-4.49$ & .448 \\
\hline & No & 329 & 58.0 & & Reference & \\
\hline \multirow[t]{2}{*}{ Allow students to bring bicycles* } & Yes & 534 & 94.2 & 3.29 & $0.48-22.42$ & .224 \\
\hline & No & 33 & 5.8 & & Reference & \\
\hline \multirow[t]{2}{*}{ Allow students to bring small wheel vehicles ${ }^{\dagger}$} & Yes & 351 & 61.9 & 2.72 & $0.94-7.84$ & .064 \\
\hline & No & 216 & 38.1 & & Reference & \\
\hline \multirow[t]{2}{*}{ Encourage use of helmets and safety gear* } & Yes & 544 & 95.9 & 1.17 & $0.14-9.53$ & .887 \\
\hline & No & 23 & 4.1 & & Reference & \\
\hline \multirow[t]{2}{*}{ Organize events (i.e. walk to school days) } & Yes & 131 & 23.1 & 1.25 & $0.38-4.13$ & .718 \\
\hline & No/don't know & 436 & 76.9 & & Reference & \\
\hline \multirow[t]{2}{*}{ Access to bike racks during school hours* } & Yes, on grounds only & 527 & 92.9 & 2.98 & $0.50-17.70$ & .229 \\
\hline & No & 40 & 7.1 & & Reference & \\
\hline \multirow[t]{2}{*}{ Bikes stored in a secure area } & Yes & 383 & 67.5 & 1.38 & $0.45-4.22$ & .571 \\
\hline & No/don't know & 184 & 32.5 & & Reference & \\
\hline \multirow[t]{3}{*}{ Religious tension perceived as problem* } & Major/moderate & 43 & 7.6 & 1.73 & $0.29-10.13$ & .544 \\
\hline & Minor & 153 & 27.0 & 1.68 & $0.43-6.62$ & .459 \\
\hline & No problem or don't know & 372 & 65.4 & & Reference & \\
\hline \multirow[t]{3}{*}{ Garbage/litter perceived as problem* } & Major/moderate & 52 & 9.2 & 3.31 & $0.66-16.52$ & .145 \\
\hline & Minor & 235 & 41.4 & 1.69 & $0.52-5.47$ & .380 \\
\hline & No problem or don't know & 280 & 49.4 & & Reference & \\
\hline \multirow[t]{3}{*}{ Drugs/drinking perceived as problem* } & Major/moderate & 30 & 5.3 & 4.36 & $0.78-24.54$ & .094 \\
\hline & Minor & 92 & 16.2 & 0.72 & $0.14-3.56$ & .683 \\
\hline & No/don't know & 445 & 78.5 & & Reference & \\
\hline \multirow[t]{3}{*}{ Gangs perceived as problem* } & Major/moderate & 25 & 4.4 & 3.98 & $0.64-24.87$ & .140 \\
\hline & Minor & 45 & 7.9 & 1.47 & $0.27-7.99$ & .654 \\
\hline & No problem or don't know & 497 & 87.7 & & Reference & \\
\hline \multirow[t]{3}{*}{ Traffic perceived as problem } & Major/moderate & 126 & 22.2 & 3.41 & $0.86-13.56$ & .081 \\
\hline & Minor & 254 & 44.8 & 1.30 & $0.39-4.37$ & .671 \\
\hline & No problem or don't know & 187 & 33.0 & & Reference & \\
\hline \multirow[t]{3}{*}{ Vacant/shabby housing perceived as problem* } & Major/moderate & 28 & 4.9 & 4.11 & $0.73-23.32$ & .110 \\
\hline & Minor & 43 & 7.6 & 4.26 & $0.58-31.15$ & .153 \\
\hline & No problem or don't know & 496 & 87.5 & & Reference & \\
\hline \multirow[t]{3}{*}{ Crime perceived as problem* } & Major/moderate & 33 & 5.8 & 5.99 & $1.24-28.87$ & .026 \\
\hline & Minor & 190 & 33.5 & 1.89 & $0.57-6.29$ & .302 \\
\hline & No problem or don't know & 344 & 60.7 & & Reference & \\
\hline
\end{tabular}


Table 3 School-level correlates of active school transport, as observed in the school audit ${ }^{\dagger}$

\begin{tabular}{|c|c|c|c|c|c|c|}
\hline Variable & Categories & Frequency & Percentage & OR & $95 \% \mathrm{Cl}$ & $p$ \\
\hline \multirow[t]{2}{*}{ Predominant land use around school* } & Residential & 508 & 89.6 & 0.64 & $0.14-2.95$ & 643 \\
\hline & Others & 59 & 10.4 & & Reference & \\
\hline \multirow[t]{2}{*}{ Place where parents can stop and drop children off* } & No & 8 & 1.4 & 7.69 & $0.72-81.90$ & .091 \\
\hline & Yes & 559 & 98.6 & & Reference & \\
\hline \multirow[t]{2}{*}{ Place where parents can park their cars* } & No & 88 & 15.5 & 2.32 & $0.44-12.16$ & .319 \\
\hline & Yes & 479 & 84.5 & & Reference & \\
\hline \multirow[t]{2}{*}{ Bus stop } & No & 85 & 15.0 & 2.00 & $0.57-7.02$ & .276 \\
\hline & Yes & 482 & 85.0 & & Reference & \\
\hline \multirow[t]{2}{*}{ Cycle lane separated from the road* } & No & 567 & 100.0 & & \multirow{2}{*}{$\mathrm{N} / \mathrm{A}$} & \\
\hline & Yes & 0 & 0.0 & & & \\
\hline \multirow[t]{2}{*}{ Cycle lane on the road } & No & 531 & 93.7 & 0.46 & $0.03-6.48$ & .556 \\
\hline & Yes & 36 & 6.3 & & Reference & \\
\hline \multirow[t]{2}{*}{ Sidewalks on both sides ${ }^{\ddagger}$} & No & 93 & 16.4 & 3.07 & $0.85-11.04$ & .086 \\
\hline & Yes & 474 & 83.6 & & Reference & \\
\hline \multirow[t]{2}{*}{ Sidewalks on one side only } & No & 328 & 57.8 & 0.37 & $0.13-1.04$ & .060 \\
\hline & Yes & 239 & 42.2 & & Reference & \\
\hline \multirow[t]{2}{*}{ Marked pedestrian crossing } & No & 104 & 18.3 & 3.17 & $0.98-10.27$ & .054 \\
\hline & Yes & 463 & 81.7 & & Reference & \\
\hline \multirow[t]{2}{*}{ Traffic calming measures } & No & 333 & 58.7 & 4.05 & $1.52-10.79$ & .005 \\
\hline & Yes & 234 & 41.3 & & Reference & \\
\hline \multirow[t]{2}{*}{ School warning sign for road users* } & No & 11 & 1.9 & 1.12 & 0.07-19.16 & .937 \\
\hline & Yes & 556 & 98.1 & & Reference & \\
\hline \multirow[t]{2}{*}{ Road safety sign } & No & 56 & 9.9 & 1.29 & $0.32-5.12$ & .722 \\
\hline & Yes & 501 & 90.1 & & Reference & \\
\hline \multirow[t]{2}{*}{ Route sign for cyclists } & No & 437 & 77.1 & 0.55 & $0.16-1.91$ & .345 \\
\hline & Yes & 130 & 22.9 & & Reference & \\
\hline \multirow[t]{2}{*}{ Fast food restaurants } & No & 352 & 62.1 & 0.41 & $0.14-1.20$ & .102 \\
\hline & Yes & 215 & 37.9 & & Reference & \\
\hline
\end{tabular}

Note: Odds ratios for engaging in active transportation were estimated using generalized linear mixed models adjusted only for school clustering. ${ }^{*}$ Denotes that fewer than 5 schools have one of the categories being compared; these results should be interpreted with caution. ${ }^{\dagger}$ For all school audit items except land uses, the auditor was asked to specify if any of the items were visible from any school entrance. " If any of the road segments observed had sidewalks on both sides, this item was coded as yes.

the ICC, the more students attending the same school used the same travel mode. Second, socio-demographic variables were added as fixed effects in the model adjusted for school clustering. Only variables that were significant at the 0.05 level were kept in the model, and interactions among these variables were examined. Third, school-level factors were individually added to the model developed in step 2. Only school-level factors that were significant at the 0.05 level were retained for the final model. The school audit item pertaining to bike lanes separated from the road was omitted, because this feature was absent in all schools. Fourth, a final model was fitted with the socio-demographic and school level correlates that were found to be significantly associated with AST, and interactions among these variables were examined. All analyses were performed using IBM SPSS version 21 (Armonk, United States).

\section{Results}

Descriptive characteristics of the sample are shown in Tables 1, 2, 3. 35.1\% of participants reported that they regularly engaged in AST (33.9\% walking and 1.3\% other active modes). Conversely, $38.6 \%$ of participants reported using public transportation (i.e., school buses) and $26.3 \%$ traveled by car. Approximately half of the participants reported school travel times between 5 and 15 minutes while the remainder was rather evenly distributed across the $<5$ minutes and $\geq 15$ minutes categories. Parents reported relatively high income and over half of the mothers had received university education. $42.1 \%$ of 
parents owned $\leq 1$ motorized vehicles while $57.9 \%$ owned $\geq 2$ vehicles. In general, most school administrators indicated having written PA and healthy eating policies in place, and their school reportedly encouraged AST through various strategies. School administrators tended to perceive the school neighbourhood as relatively safe, and the most frequently reported concern was traffic safety. Broadly speaking, the school audit revealed that most schools were located in predominantly residential areas and there was generally good infrastructure to support walking. However, provision of cycling infrastructure was very poor with few bike lanes and traffic signs for cyclists.

The initial GLMM indicated large clustering of AST at the school level (ICC $=0.31 ; p=0.005$ ), emphasizing the importance of controlling for school clustering. In models adjusted only for school clustering, boys $(\mathrm{OR}=1.98 ; 95 \% \mathrm{CI}=1.31-2.98)$ and participants reporting school trip durations of $<5$ minutes $(\mathrm{OR}=2.39 ; 95 \% \mathrm{CI}=$ 1.24-4.63) or 5-15 minutes $(\mathrm{OR}=2.44 ; 95 \% \mathrm{CI}=1.37-4.34$ ) were significantly more likely to engage in AST compared to girls and those with travel times $>15$ minutes (Table 1). No interactions were observed between gender and school travel time (data not shown). Income, mother's education, car ownership and school board (e.g., public or catholic) were not associated with AST. However, lower odds of AST were noted in children attending French schools $(\mathrm{OR}=0.19 ; 95 \% \mathrm{CI}=0.06-0.64)$.

Table 2 shows that three of the administrator survey items were significantly associated with AST. Specifically, children were more likely to engage in AST if administrators reported that the school identified safe routes to school $(\mathrm{OR}=3.63 ; 95 \% \mathrm{CI}=1.39-9.44)$ or that crossing guards were employed $(\mathrm{OR}=5.75 ; 95 \% \mathrm{CI}=2.52-13.10)$. If administrators perceived that crime was a major or moderate problem in the school neighbourhood children were more likely to engage in AST than if crime was not perceived as a problem $(\mathrm{OR}=5.99 ; 95 \% \mathrm{CI}=1.24-28.87)$. This effect should be interpreted cautiously given that only three administrators (representing 33 students) perceived crime as a major or moderate problem. Finally, if traffic calming measures (i.e., speed bumps, narrower lanes) were observed during the school audit, children were significantly more likely to be active travelers $(\mathrm{OR}=4.05 ; 95 \% \mathrm{CI}=1.52-10.79)$.

In the fully adjusted model (Table 4), the observed associations of gender and school travel time remained

Table 4 Multivariate associations of socio-demographic and school-level factors with children's engagement in active transportation

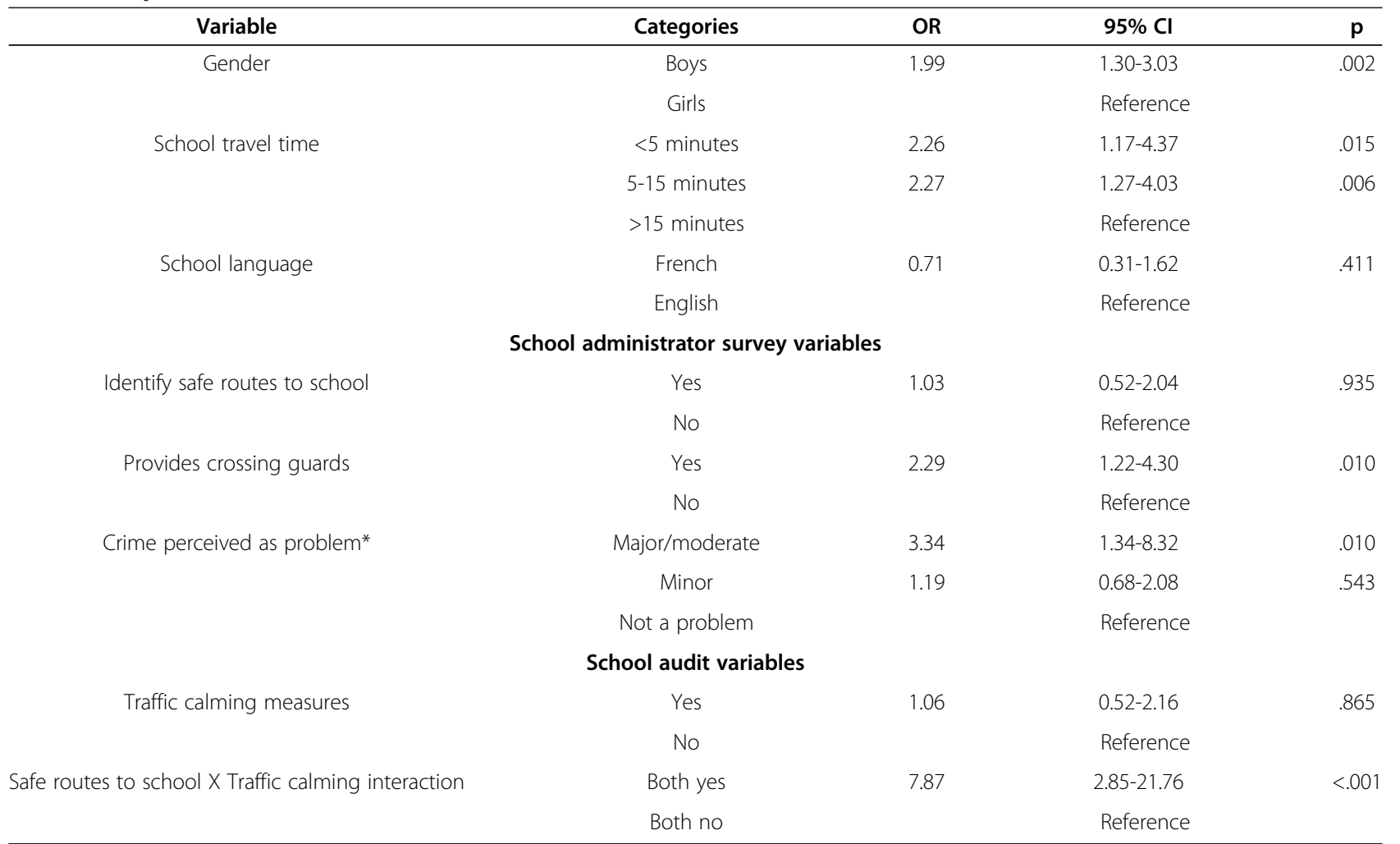

Note: Odds ratios for engaging in active transportation were estimated using generalized linear mixed models adjusted only for school clustering. Only variables that were significantly associated with active school transport in the bivariate models (e.g., Tables 1, 2, 3) were included in the multivariate model. In the empty model, the school ICC was 0.31 ( $<<0.001)$ while in the fully adjusted model, it was $0.01(p=0.718)$. *Denotes that fewer than 5 schools have one of the categories being compared; these results should be interpreted with caution. 
significant and their effect sizes remained virtually unchanged. Specifically, boys $(\mathrm{OR}=1.99 ; 95 \% \mathrm{CI}=1.30-3.03)$ and participants reporting school trip durations of $<5 \mathrm{mi}-$ nutes $(\mathrm{OR}=2.26 ; 95 \% \mathrm{CI}=1.17-4.37)$ or $5-15$ minutes $(\mathrm{OR}=2.27 ; 95 \% \mathrm{CI}=1.27-4.03)$ were more likely to engage in AST. The provision of crossing guards was also associated with greater odds of AST (OR $=2.29$; 95\% $\mathrm{CI}=1.22-4.30$ ). Again, if administrators perceived that crime was a major or moderate problem in the school neighbourhood, children were more likely to use AST $(\mathrm{OR}=3.34 ; 95 \% \mathrm{CI}=1.34-8.32)$. Finally, an interaction was observed between the identification of safe routes to school and the presence of traffic calming measures (Figure 1). If both features were present (i.e., safe routes to school combined with traffic calming measures), children were almost eight times more likely to engage in AST $(\mathrm{OR}=7.87 ; 95 \% \mathrm{CI}=2.85-21.76)$. If only one of these features were present, it was not associated with a greater likelihood of AST. Differences between children attending French vs. English schools were no longer significant. The final model explained most of the clustering of AST at the school level as shown by the very small ICC of $0.01(\mathrm{p}=0.718)$.

\section{Discussion}

The present study assessed the socio-demographic and school-level correlates of AST among 10-year-old children in Ottawa, Canada. Analyses indicated that approximately $31 \%$ of the variance in AST was explained at the school level. The final model shows that boys, children whose school journey was shorter, and those attending schools where crossing guards were employed were approximately twice as likely to engage in AST. When school administrators reported that crime in the school neighbourhood was a major or moderate problem, children were over three times more likely to engage in AST. Of particular interest, there was a synergy between the identification of safe routes to school (as reported by administrators) and the presence of traffic calming measures (ascertained by the study team). Specifically, when both of these characteristics were present, children were almost eight times more likely to engage in AST. Collectively, these findings should be relevant for policy-makers, education leaders, public health workers, and urban/transport planners interested in facilitating children's AST.

To our knowledge, no previous study has reported such a synergy between the identification of safe routes to

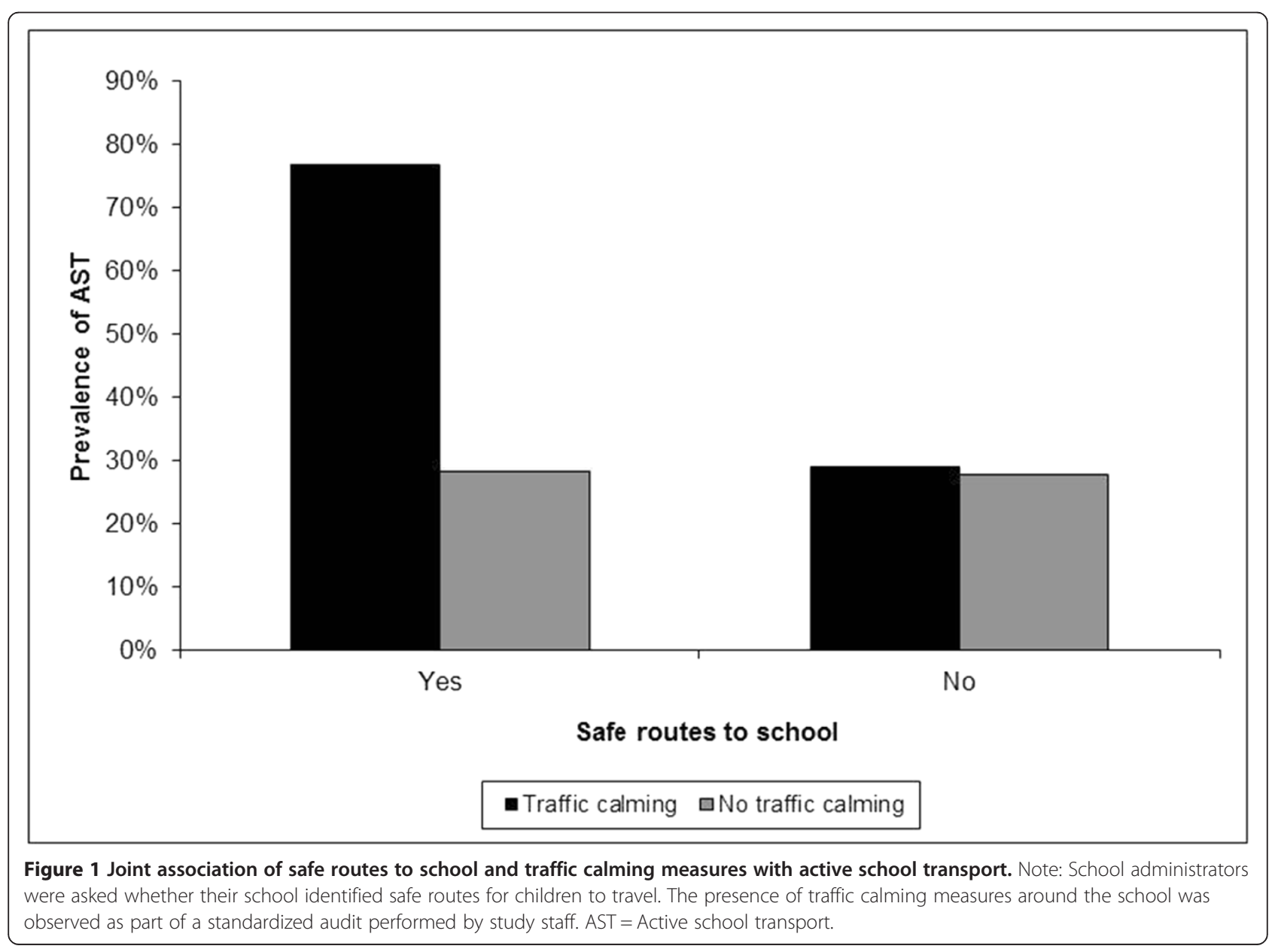


school and the presence of traffic calming measures in the vicinity of the school. Nevertheless, this finding is consistent with a recent evaluation of the Safe Routes to School program in Oregon, United States [28]. Specifically, McDonald and colleagues [28] reported that more comprehensive interventions (including education and encouragement programs combined with infrastructure improvements) were more effective, achieving 5-20 percentage points increases in walking and cycling. Together, these findings suggest substantial interactions between the social environment and the built environment, as postulated by social ecological models $[15,16]$. Nevertheless, this relationship could also be driven by unmeasured variables such as the average distance between home and school $[26,29]$ or neighbourhood walkability $[17,30]$ which are known to influence travel behaviours. This underscores a need for further studies.

Interestingly, neither the identification of safe routes to school nor the presence of traffic calming measures was independently associated with children's AST in the adjusted model. This finding may suggest that interventions focusing only on the promotion of AST or on infrastructure changes may be insufficient to trigger behaviour change. Of particular interest, the Canadian school travel planning model uses a comprehensive approach where school specific interventions are developed to change travel behaviours and improve safety based on input from members of the school community (e.g., students, parents, and teachers) and other stakeholders [26]. Recent evaluations of this approach have revealed either a modest increase in AST [26] or no significant differences in travel behaviours [12]. These somewhat disappointing results may be attributable to the fact that schools were followed for only one year, and this time frame is likely too short for comprehensive school travel plans to be fully implemented, or their impact realized [12]. This hypothesis is supported by the results of the New Zealand school travel planning intervention which indicated significant increases in AST after three years of implementation, but not after only one year [31]. Hence, there remains a need for longer investigations examining the effectiveness of this program as well as moderators and mediators of behaviour change.

AST was also strongly associated with the presence of crossing guards, as reported by the school administrators. This finding is consistent with recent studies in the city of Toronto [32], the United States [33], and the United Kingdom [19]. Interestingly, hiring crossing guards may represent an easier (and relatively inexpensive) strategy to encourage AST compared to major built environment changes [32].

Notably, children were more likely to engage in AST if school principals perceived that crime was a major or moderate problem in the school neighbourhood. While counter-intuitive, this finding is in agreement with previous research reporting a greater likelihood of AST if parents did not perceive their neighbourhood as safe [34] or as an excellent area to raise a child [35]. Other researchers also reported higher rates of AST in areas characterized by greater incivilities [36]. Nevertheless, longitudinal studies are warranted to examine whether such associations may be attributable to reverse causality; e.g., school officials may be more concerned about neighbourhood safety if they are aware that a large proportion of students walk or cycle to/from school. In addition, several North American studies have reported higher rates of AST in low SES areas $[18,37,38]$ where motorized travel may not be an available option. In the present study, area deprivation (as estimated using the median household income of the census tract in which the schools were located) was not associated with AST (data not shown).

The observation that children who had longer journeys to school were less likely to engage in AST is consistent with previous literature reviews indicating that long distance between home and school is a major barrier to AST [26,29]. Furthermore, Torres et al. [39] reported lower rates of AST among children attending English schools in Montréal and Trois-Rivières (Québec) and noted that these children traveled greater distances to/from school. Our results show a similar association whereby children attending minority language schools (in this case, French) were approximately five times less likely to engage in AST after adjustment for school clustering. This association was no longer significant in the fully-adjusted model which included school travel time as a proxy for home-school distance. While it may not be feasible for children living far away from their school to do the entire trip on foot, a drop off zone could be designated within a "walkable" distance, so that children who are driven to school by car or bus can engage in some AST [40]. For example, a partnership was successfully developed to allow school buses to use the parking lot of a nearby church as part of a Safe Routes to School intervention in Atlanta, United States [41].

In the present study, boys were twice as likely as girls to engage in AST. This observation is consistent with many North American studies reporting higher rates of AST in boys $[18,37,42,43]$. Furthermore, at any given age, boys generally have greater independent mobility than girls $[44,45]$. Independent mobility refers to "the freedom of children to travel around their own neighbourhood without adult supervision" [46] and it has been repeatedly shown to be associated with greater AST and PA levels [47-49]. However, in Denmark, where cycling to school is much more prevalent and safer, no gender gaps have been reported [3].

The present findings should be interpreted cautiously given the cross-sectional study design which makes it 
impossible to determine the direction of the observed relationships. Moreover, the correlates of children's current travel mode may differ from those of travel behaviour change, emphasizing a need for longitudinal investigations. A second limitation to consider is that all participating schools were recruited in the Ottawa region, so it is unclear whether similar associations would have been found elsewhere. However, multiple studies of correlates of AST have found associations with variables such as distance $[26,29]$ and the presence of crossing guards $[19,32,33]$ in various jurisdictions. Third, although walking and cycling may have different correlates, it was unfeasible to examine them separately owing to the scarcity of cycling in the sample. Fourth, only environmental characteristics around the school were examined. Previous research suggests that characteristics of the home neighbourhood and the route between home and school may also influence children's travel behaviours $[13,19]$. Fifth, the reliability and validity of the travel mode questions was not assessed. However, previous research suggests that similar questions have high test-retest reliability and convergent validity between child and parent reports [50,51]. Furthermore, three studies have examined the test-retest reliability of school travel time questions among children of this age, and they all reported high coefficients (ICC ranging from 0.70 to 0.94 ), indicating that children can provide reliable estimates [52-54]. Finally, the relatively small number of clusters (e.g., 26 schools) may have led to lesser precision in the estimates as suggested by the large confidence intervals observed for many of the school-level factors.

However, the examination of the relative influence of socio-demographic and school-level correlates of AST while controlling for school clustering is an important strength of the study. Previous Canadian studies had shown large between-school variation in AST $[18,55,56]$. By identifying the factors accounting for the clustering of AST at the school level, the present study provides valuable insights for future school-based interventions and policies. Second, school-level factors were examined both from the perspective of school administrators and from a school audit performed by the study team, thus providing complementary information on a wide range of potential correlates of AST. Third, the sample was stratified according to school language and school board. After adjustment for school clustering, children attending French schools were about five times less likely to engage in AST, suggesting that interventions and policies targeting this minority population may be needed. Finally, complete data were available for all of the variables included in the final model.

\section{Conclusion}

This study found that boys, children reporting shorter school journeys, and those attending schools where crossing guards were employed or where school administrators expressed concerns about crime in the school neighbourhood were more likely to engage in AST. Furthermore, there was a strong synergy between the identification of safe routes to school and the presence of traffic calming measures in the school neighbourhood, suggesting that these strategies should be used in combination. Together, these variables explained the majority of the clustering of AST at the school level. Future longitudinal studies should examine these variables as potential correlates of travel behaviour change in the context of AST interventions.

\section{Competing interests}

The authors declare that they have no competing interests.

\section{Authors' contributions}

RL, JPC and MST conceived the analysis plan. RL conducted the statistical analyses and drafted the manuscript. GL coordinated the study and $C B, P B, A G L$ and MMB were involved in data collection. JPC and MST were the Principal Investigators for the Canadian ISCOLE site. All authors carefully reviewed and commented the first draft and approved the submitted version.

\section{Acknowledgements}

We would like to thank Claire Francis, Jessica McNeil, Nina Azoug-Boneault and Hadiza Amedu-Ode for their role in data collection for the Canadian site of ISCOLE, and the Coordinating Center of ISCOLE in Baton Rouge, Louisiana, specifically Drs. Peter Katzmarzyk and Timothy Church. We would also like to thank the study participants along with their parents, teachers and school principals for their involvement in the study. The ISCOLE study was funded by the Coca-Cola Company. The funder had no role in study design, data collection and analysis, decision to publish, or preparation of the manuscript. The authors also wish to thank Dr. Nick Barrowman for his advice on the statistical analyses.

\section{Author details}

${ }^{1}$ Healthy Active Living and Obesity Research Group, Children's Hospital of Eastern Ontario Research Institute, 401 Smyth Road, Room R242, Ottawa, ON K1H 8 L1, Canada. ${ }^{2}$ Department of Pediatrics, University of Ottawa, Ottawa, Canada.

Received: 20 February 2014 Accepted: 14 May 2014

Published: 23 May 2014

\section{References}

1. Larouche R, Saunders T, Faulkner GEJ, Colley RC, Tremblay MS: Associations between active school transport and physical activity, body composition and cardiovascular fitness: a systematic review of 68 studies. J Phys Act Health 2014, 11(1):206-227.

2. Lubans DR, Boreham CA, Kelly P, Foster CE: The relationship between active travel to school and health-related fitness in children and adolescents: a systematic review. Int J Behav Nutr Phys Act 2011, 8(5).

3. Cooper AR, Wedderkopp N, Wang N, Andersen LB, Froberg K, Page AS: Active travel to school and cardiovascular fitness in Danish children and adolescents. Med Sci Sports Exerc 2006, 38(10):1724-1731.

4. Larouche R, Faulkner GEJ, Fortier M, Tremblay MS: Active transportation and adolescents' health: the Canadian Health Measures Survey. Am J Prev Med 2014, 46(5):507-515.

5. AVENA Study Group, Martinez-Gomez D, Ruiz JR, Gomez-Martinez S, Chillon P, Rey-Lopez P, Diaz LE, Castillo R, Veiga OL, Marcos A: Active commuting to school and cognitive performance in adolescents. Arch Pediatr Adolesc Med 2011, 165(4):300-305.

6. Lambiase MJ, Barry HM, Roemmich JN: Effect of a simulated active commute to school on cardiovascular stress reactivity. Med Sci Sports Exerc 2010, 42(8):1609-1616.

7. van der Ploeg HP, Merom D, Corpuz G, Bauman AE: Trends in Australian children traveling to school 1971-2003: burning petrol or carbohydrates? Prev Med 2008, 46(1):60-62. 
8. Buliung RN, Mitra R, Faulkner G: Active school transportation in the Greater Toronto area, Canada: an exploration of trends in space and time (1986-2006). Prev Med 2009, 48(6):507-512.

9. Grize L, Bringolf-Isler B, Martin E, Braun-Farhländer C: Trend in active transportation to school among Swiss school children and its associated factors: three cross-sectional surveys 1994, 2000 and 2005. Int J Behav Nutr Phys Act 2010, 7:28.

10. McDonald NC: Active commuting to school: trends among US schoolchildren 1969-2001. Am J Prev Med 2007, 32(6):509-516.

11. Chillón P, Evenson KR, Vaughn A, Ward DS: A systematic review of interventions for promoting active transportation to school. Int J Behav Nutr Phys Act 2011, 8(10).

12. Mammen G, Stone MR, Faulkner G, Ramanathan S, Buliung R, O'Brien C, Kennedy J: Active school travel: an evaluation of the Canadian school travel planning intervention. Prev Med 2014, 60:55-59.

13. Panter JR, Jones AP, Van Sluijs EMF: Environmental determinants of active travel in youth: a review and framework for future research. Int J Behav Nutr Phys Act 2008, 5:34.

14. Pont K, Ziviani J, Wadley D, Abbott R: The model of children's active travel (M-CAT): A conceptual framework for examining factors influencing children's active travel. Aust Occup Ther J 2011, 58:138-144.

15. Giles-Corti B, Timperio A, Bull F, Pikora T: Understanding physical activity environmental correlates: increased specificity for ecological models. Exerc Sport Sci Rev 2005, 33(4):175-181.

16. Sallis JF, Cervero RB, Ascher W, Hendersen KA, Kraft MK, Kerr J: An ecological approach to creating active living communities. Annu Rev Public Health 2006, 27:297-322.

17. Christiansen LB, Toftager M, Schipperijin J, Ersbø\|l AK, Giles-Corti B, Troelsen $\mathrm{J}$ : School site walkability and active school transport - association, mediation and moderation. J Transport Geogr 2014, 34:7-15.

18. Gropp K, Pickett W, Janssen I: Multi-level examination of correlates of active transportation to school among youth living within 1 mile of their school. Int J Behav Nutr Phys Act 2012, 9:124

19. Panter JR, Jones AP, Van Sluiis EMF, Griffin SJ: Neighborhood, route and school environments and children's active commuting. Am J Prev Med 2010, 38(3):268-278.

20. Cerin E: Statistical approaches to testing the relationships of the built environment with resident-level physical activity behavior and health outcomes in cross-sectional studies with cluster sampling. J Plan Lit 2011, 26(2):151-167.

21. Katzmarzyk PT, Barreira TV, Broyles ST, Champagne CM, Chaput J-P, Fogelholm M, Hu G, Johnson WD, Kuriyan R, Kurpad A, Lambert EV, Maher C, Maia J, Matsudo V, Olds T, Onywera V, Sarmineto OL, Strandage M, Tremblay MS, Tudor-Locke C, Zhao P, Church TS: The international study of childhood obesity, lifestyle and the environment (ISCOLE): design and methods. BMC Public Health 2013, 13:900.

22. Statistics Canada: Focus on geography series, 2011 census. 2012 [http://www12.statcan.ca/census-recensement/2011/as-sa/fogs-spg/ Facts-cma-eng.cfm?LANG=Eng\&GK=CMA\&GC $=505]$.

23. Cameron R, Manske S, Brown KS, Jolin MA, Murnaghan D, Lovato C: Integrating public health policy, practice, evaluation, surveillance, and research: the school health action planning and evaluation system. Am J Public Health 2007, 97(4):648-654.

24. Kroeker C, Manske S: Pilot Phase of the 2007-2008 School Health Environment Survey: Technical Report. Waterloo, ON: Center for Behavioural Research and Program Evaluation, University of Waterloo; 2008.

25. Jones NR, Jones A, Van Sluijs EM, Panter J, Harrison F, Griffin SJ: School environments and physical activity: the development and testing of an audit tool. Health Place 2010, 16(5):776-783.

26. Wong BYM, Faulkner G, Buliung R: GIS measured environmental correlates of active school transport: A systematic review of 14 studies. Int J Behav Nutr Phys Act 2011, 8(39).

27. Buliung RN, Faulkner G, Beesley T, Kennedy J: School travel planning: mobilizing school and community resources to encourage active school transportation. J Sch Health 2011, 81(11):704-712.

28. McDonald NC, Yang Y, Abbott SM, Bullock AN: Impact of the Safe Routes to School program on walking and biking: Eugene, Oregon study. Transport Policy 2013, 29:243-248.

29. Stewart O: Findings from research on active transportation to school and implications for Safe Routes to School programs. J Plan Lit 2011, 26(2):127-150
30. Ding D, Sallis JF, Kerr JK, Lee S, Rosenberg DE: Neighborhood environment and physical activity among youth: a review. Am J Prev Med 2011, 41:442-455

31. Hinckson EA, Garrett N, Duncan S: Active commuting to school in New Zealand Children (2004-2008): A quantitative analysis. Prev Med 2011, 52:332-336

32. Rothman L, To T, Buliung R, Macarthur C, Howard A: Influence of social and built environment features on children walking to school: an observational study. Prev Med 2014, 60:10-15.

33. Chriqui JF, Taber DR, Slater SJ, Turner L, Lowrey KM, Chaloupka FJ: The impact of state safe routes to school-related laws on active travel to school policies and practices in U.S. elementary schools. Health Place 2012, 18(1):8-15.

34. Mendoza JA, Liu Y: Active commuting to elementary school and adiposity: an observational study. Child Obes 2014, 10(1):1-8.

35. Pabayo R, Gauvin L, Barnett TA, Morency P, Nikiéma B, Séguin L: Understanding the determinants of active transportation to school among children: evidence of environmental injustice from the Quebec Longitudinal Study of Child Development. Health Place 2012, 18(2):163-171

36. Rossen LM, Pollack KM, Curriero FC, Shields TM, Smart MJ, Furr-Holden DM, Cooley-Strikland M: Neighborhood incivilities, perceived neighborhood safety, and walking to school among urban-dwelling children. J Phys Act Health 2011, 8(2):262-271.

37. Evenson KR, Huston SL, McMillen BJ, Bors P, Ward DS: Statewide prevalence and correlates of walking and bicycling to school. Arch Pediatr Adolesc Med 2003, 157(9):887-892.

38. Pabayo R, Gauvin L, Barnett TA: Longitudinal changes in active transportation to school in Canadian youth aged 6 through 16 years. Pediatrics 2011, 128(2):e404-e413.

39. Torres J, Bussière Y, Lewis P: Primary schools` territorial policy and active commuting: institutional influences in Montréal and Trois-Rivières. J Urban Plann Dev 2010, 136(4):287-293.

40. Larouche R, Barnes J, Tremblay MS: Too far to walk or bike? Can J Public Health 2013, 104(7):e487-e489.

41. Henderson S, Tanner R, Klanderman N, Mattera A, Webb LM, Steward J: Safe Routes to School: a public health practice success story - Atlanta, 2008-2010. J Phys Act Health 2013, 10:141-142.

42. Fulton JE, Shisler JL, Yore MM, Caspersen CJ: Active transportation to school: Findings from a national survey. Res Q Exerc Sport 2005, 76:352-357

43. McMillan T, Day K, Boarnet M, Alfonzo M, Anderson C: Johnny walks to school - does Jane? Sex differences in children's active travel to school. Child Youth Environ 2006, 16(1):75-89.

44. McDonald NC: Is there a gender gap in school travel? An examination of US children and adolescents. J Transp Geogr 2012, 20:80-86.

45. Valentine G: "Oh yes I can." "Oh no you can't": Children and parents' understanding of kids' competence to negotiate public space safely. Antipode 1997, 29:65-89.

46. Tranter P, Whitelegg J: Children's travel behaviour in Canberra: car-dependent lifestyles in a low density city. J Transp Geogr 1994, 2:265-273.

47. Mackett R, Brown B, Gong Y: Children's independent movement in the local environment. Built Environ 2007, 33:454-468.

48. Page AS, Cooper AR, Griew P: Independent mobility in relation to weekday and weekend physical activity in children aged 10-11 years: the PEACH project. Int J Behav Nutr Phys Act 2009, 7:2.

49. Stone MR, Faulkner GEJ, Mitra R, Buliung RN: The freedom to explore: examining the influence of independent mobility on weekday, weekend and after-school physical activity behaviour in children living in urban and inner-suburban neighbourhoods of varying socio-economic status. Int J Behav Nutr Phys Act 2014, 11:5

50. Bere $E$, Bjorkelund LA: Test-retest reliability of a new self reported comprehensive questionnaire measuring frequencies of different modes of adolescents commuting to school and their parents commuting to work - the ATN questionnaire. Int J Behav Nutr Phys Act 2009, 6(68).

51. Evenson KR, Neelon B, Ball SC, Vaughn A, Ward DS: Validity and reliability of a school travel survey. J Phys Act Health 2008, 5(Suppl 1):S1-S15.

52. Brug J, Van Stralen MM, Chinapaw MJM, De Bourdeaudhuij I, Lien N, Bere E, Singh AS, Maes L, Moreno L, Jan N, Kovacs E, Lobstein T, Manios $Y$, Te Velde SJ: Differences in weight status and energy-balance related behaviours according to ethnic background among adolescents in 
seven countries in Europe: the ENERGY project. Pediatr Obes 2012, 7:399-411.

53. Ducheyne F, De Bourdeaudhuij I, Lenoir M, Cardon G: Test-retest reliability and validity of a child and parental questionnaire on specific determinants of cycling to school. Pediatr Exerc Sci 2012, 24:289-311.

54. Singh AS, Vik FN, Chinapaw MJM, Uijtdewilligen L, Verloigne M, Fernandez-Alvera $J M$, Stomfai S, Manios Y, Martens M, Brug J: Test-retest reliability and construct validity of the ENERGY-child questionnaire on energy balance-related behaviours and their potential determinants: the ENERGY-project. Int J Behav Nutr Phys Act 2011, 8:36.

55. Larouche R, Faulkner G, Tremblay MS: Correlates of active school travel immediately before and after the transition from primary to secondary school: a pilot-study. J Appl Res Children 2013, 4(2)

56. Mitra R, Buliung RN, Faulkner GEJ: Spatial clustering and the temporal mobility of walking school trips in the Greater Toronto Area, Canada. Health Place 2010, 16(4):646-655.

doi:10.1186/1471-2458-14-497

Cite this article as: Larouche et al: A cross-sectional examination of socio-demographic and school-level correlates of children's school travel mode in Ottawa, Canada. BMC Public Health 2014 14:497.

\section{Submit your next manuscript to BioMed Central and take full advantage of:}

- Convenient online submission

- Thorough peer review

- No space constraints or color figure charges

- Immediate publication on acceptance

- Inclusion in PubMed, CAS, Scopus and Google Scholar

- Research which is freely available for redistribution 